\title{
The Role of Hox Genes in Female Reproductive Tract Development, Adult Function, and Fertility
}

\author{
Hongling Du and Hugh S. Taylor \\ Department of Obstetrics, Gynecology and Reproductive Sciences, Yale University School of Medicine, \\ New Haven, Connecticut 06520 \\ Correspondence: hugh.taylor@yale.edu
}

HOX genes convey positional identity that leads to the proper partitioning and adult identity of the female reproductive track. Abnormalities in reproductive tract development can be caused by HOX gene mutations or altered HOX gene expression. Diethylstilbestrol (DES) and other endocrine disruptors cause Müllerian defects by changing HOX gene expression. HOX genes are also essential regulators of adult endometrial development. Regulated HOXA1O and HOXA11 expression is necessary for endometrial receptivity; decreased HOXA10 or HOXA11 expression leads to decreased implantation rates. Alternation of HOXA10 and HOXA11 expression has been identified as a mechanism of the decreased implantation associated with endometriosis, polycystic ovarian syndrome, leiomyoma, polyps, adenomyosis, and hydrosalpinx. Alteration of HOX gene expression causes both uterine developmental abnormalities and impaired adult endometrial development that prevent implantation and lead to female infertility.

$H$ OX genes comprise a family of regulatory molecules that encode highly conserved transcription factors. In the past several decades, molecular and genetic evidence indicates that HOX genes are expressed along anteriorposterior axes and control morphogenesis and cell differentiation during normal embryonic axial development; this mechanism for assigning differential identity along previously uniform axes is used in species as diverse as Drosophila and humans (McGinnis and Krumlauf 1992). HOX genes have a similar role in the specification of the developmental fate in individual regions of the female reproductive tract, where they regulate developmental axis in the embryonic period. HOX genes also give specific identity to the developing endometrium during the menstrual cycle in adults. The cyclic growth of endometrium is dependent on the ordered production of estrogen and progesterone. HOX gene expression is regulated by sex steroids, and this regulated expression plays an important role in endometrial development and endometrial receptivity (Taylor et al. 1997, 1998, 1999b). Here, we review the role of HOX genes, specifically the HOXA/Hoxa genes, in reproductive tract development, endometrial cyclic growth and embryo implantation, and the alterations in HOXA/Hoxa gene expression that can lead to infertility.

Editors: Diana W. Bianchi and Errol R. Norwitz

Additional Perspectives on Molecular Approaches to Reproductive and Newborn Medicine available

at www.perspectivesinmedicine.org

Copyright (C) 2016 Cold Spring Harbor Laboratory Press; all rights reserved; doi: 10.1101/cshperspect.a023002

Cite this article as Cold Spring Harb Perspect Med 2016;6:a023002 
H. Du and H.S. Taylor

\section{HOX GENES AND THEIR ROLE IN THE BODY PLAN}

\section{HOX Genes}

Homeobox genes (as known as HOX genes) comprise a group of highly conserved genes that are essential regulators of anterior-posterior (A-P) axial pattern development. In 1978, the relationship between the location of a homeotic gene and positional development identity was first recognized in Drosophila (Lewis 1978). Six years later, the HOX genes were cloned and sequenced in the fruit fly Drosophila melanogaster (McGinnis et al. 1984a,b; Scott and Weiner 1984). Since then, multiple HOX genes have been identified in many species, including humans. HOX genes encode proteins that act as transcription factors. In each of the HOX genes, a 183-bp highly conserved sequence was identified, which encodes a 61-amino acid region, called the homeodomain (HD). Structural analyses have shown that the HD can self-fold, and form a structural motif called a "helix-turn-helix motif." Through this motif, the HD, a DNA binding domain, recognizes a typical core DNA sequence, typically TAAT or TTAT, and regulates the expression of target genes, many of which play a role in axial development (Gehring et al. 1994; Krumlauf 1994; Gruschus et al. 1999; Passner et al. 1999).

Like all other insects, Drosophila has eight HOX genes, which are clustered into two complexes in close proximity, the antennapedia (Ant-C) complex and bithorax $(\mathrm{Bx}-\mathrm{C})$ complex. In mice and humans, Hox/HOX genes are clustered into four unlinked genomic loci, Hox a-d (mouse) or HOX A-D (human); each locus contains nine to 13 genes and all four clusters contain a total of 39 HOX genes. Those four paralogues, classified by sequence similarity, are located on chromosomes $6,11,15$, and 2 in mice and chromosomes 7, 17, 12, and 2 in humans. The clustered HOX genes are believed to have arisen from gross duplication of a single common ancestral cluster. Presently, none of the paralogues have 13 genes, so some duplicated genes must have been lost during the course of evolution (Krumlauf 1994).

\section{Hox Genes and Vertebrate Axial Development}

In general, expression of the HOX genes follows a $3^{\prime}$ to $5^{\prime}$ order, which means, HOX genes at $3^{\prime}$ end are expressed earlier in development than their $5^{\prime}$ neighbors within the same cluster. The position in the cluster reflects both the timing and spatial position of developmental expression (Hunt and Krumlauf 1992; McGinnis and Krumlauf 1992). HOX genes have a wellcharacterized role in embryonic development, during which they determine identity along the $\mathrm{A}-\mathrm{P}$ body axis. In vertebrates, gastrulation forms three germ layers: ectoderm, endoderm, and mesoderm. HOX genes are first expressed in the mesoderm during early gastrulation, and the $3^{\prime}$ genes are expressed first in anterior locations and then the $5^{\prime}$ genes are expressed later in the distal sacral regions. The role of mammalian HOX genes in regulating segmental patterns of hindbrain, skeleton axis and the limb axis is well established. In mice, gain- and loss-offunction experiments have revealed the spatiotemporal expression controlled by Hox genes in skeleton development (Ramirez-Solis et al. 1993; Horan et al. 1995; Fromental-Ramain et al. 1996; Favier and Dolle 1997). For instance, loss of Hoxb4 expression leads to defects in the first and second cervical vertebrae. Targeted mutations of Hoxa9 and Hoxd 9 result in anterior transformations of distinct lumbosacral vertebrae. There are transformations of sacral and first caudal vertebrae in Hoxa11 knockout mice. In the vertebrate nervous system, the hindbrain or rhombencephalon develops under the regulating of such segmental patterning directed by Hox gene expression as well; regional expression of Hox genes in the hindbrain is thought to confer identity to rhombomeres (Carpenter et al. 1993; Mark et al. 1993; Goddard et al. 1996; Studer et al. 1996; Morrison et al. 1997; Manzanares et al. 1999; Ferretti et al. 2000; Yau et al. 2002). Mice harboring a Hoxal mutation have alteration in hindbrain segmentation, deleting all or part of rhombomere 5 (r5). The absence of Hoxb1 function results in an apparent segmental transformation of $\mathrm{r} 4$ to an $\mathrm{r}$ 2-like rhombomere identity. Hox- is essential for $\mathrm{r} 4$ development. Hoxa3 and Hoxb3 genes are segmentally ex- 
pressed in r4 and r6. Hoxa4, Hoxb4, and Hoxd4 have anterior limits in the hindbrain, but map to the junction between rhombomeric segments r6 and r7. Vertebrate HOX genes not only specify positional identity along the $\mathrm{A}-\mathrm{P}$ axis of the body plan, but also provide positional values on the axis of the developing limb (Davis and Capecchi 1996; Nelson et al. 1996; Goff and Tabin 1997; Scott 1997). The most $5^{\prime}$ members of the Hoxa and Hoxd clusters (Hoxa9-13 and Hoxd9-13) are particularly important in vertebrate limb development. Hoxa9 to Hoxa10 and Hoxd 9 to Hoxa 10 are expressed in the developing upper arm/leg; Hoxal1 and Hoxd9 to Hoxa13 are expressed in the development of the lower part of the arm/leg. Hoxa13 and Hoxd10 to Hoxd13 are expressed during specification of the hand/foot. The first identified human limb malformation related to a defective HOX gene was synpolydactyly, which results from mutations in the HOXD13 gene (Muragaki et al. 1996). The role of HOX genes in vertebrate axial patterning is similar to but more complex than that in Drosophila. In the mice and humans, Hox/HOX gene clusters provide a considerably overlapping expression pattern, which provides for the possibility of redundancy.

\section{THE ROLE OF HOX GENES IN FEMALE REPRODUCTION}

\section{HOX Genes and Structure of Female} Reproductive Tract

The female reproductive system is derived from the paramesonephric (Müllerian) duct, which ultimately develops into the fallopian tube (oviduct), uterus, cervix, and upper part of the vagina. The developing of female reproductive tract is patterned by the differential expression of HOX genes in the Müllerian duct.

In the developing Müllerian duct, a number of posterior Abdominal $B(A b d B) H O X$ genes were found to be expressed in partially overlapping patterns along the $\mathrm{A}-\mathrm{P}$ axis. In vertebrates, HOX genes in paralogous groups Hoxa913 develop a characteristic spatial distribution throughout the Müllerian duct (Taylor et al. 1997; Taylor 2000; Goodman 2002). AbdB genes are expressed according to their $3^{\prime}$ to $5^{\prime}$ order in the HOX gene clusters. Hoxa9 is expressed at high levels in areas that will become the oviduct, Hoxa10 is expressed in the development of the uterus, Hoxa11 is found in the primordial lower uterus and cervix, and Hoxal3 is seen in the ectocervix and upper vagina. No gene exists in the Hoxa cluster that is a paralogue of Hoxd12 or Hoxc12; hence, there is no Hoxa12 gene. This expression pattern is conserved between mice and humans (Fig. 1). Targeted mutagenesis of these genes results in region-specific defects along the female reproductive tract. Hoxa10 deficiency causes the homeotic transformation of the anterior part of the uterus into an oviduct-like structure. Hoxa13 null embryos show a hypoplastic urogenital genital sinus and agenesis of the posterior portion of the Müllerian duct. When the Hoxal1 gene is replaced by the Hoxa13 gene, posterior homeotic transformation occurs in the female reproductive tract: the uterus, in which Hoxa11, but not Hoxa13 is normally expressed, becomes similar to the more posterior cervix and vagina, in which Hoxa13 is normally expressed (Satokata et al. 1995; Benson et al. 1996; Warot et al. 1997).

Although HOX genes were once considered to be expressed only during embryonic development, persistent HOX gene expression was first well characterized in the adult female reproductive tract (Benson et al. 1996; Taylor et al. 1997). The adult reproductive tract undergoes a continuing developmental process during each menstrual cycle; proliferation and differentiation of endometrium coupled with angiogenesis leads to a new endometrium in each estrus or menstrual cycle. In both mice and humans, the expression of Hoxa9-13/HOXA9-13 in the adult reproductive tract has been described as the same regions as their expression in the embryo (Dolle et al. 1991; Favier and Dolle 1997; Taylor et al. 1997; Warot et al. 1997). Specifically, Hoxa10/HOXA10 and Hoxa11/HOXA11 are expressed in the endometrium of the adult mice and humans. The expression of these two genes varies in an estrus/menstrual cycle-dependent manner (Fig. 2). Hoxa10/HOXA10 and Hoxa11/HOXA11 are expressed in the proliferative phase of the endometrium and increase during the secretory phase (Taylor et al. 
H. Du and H.S. Taylor

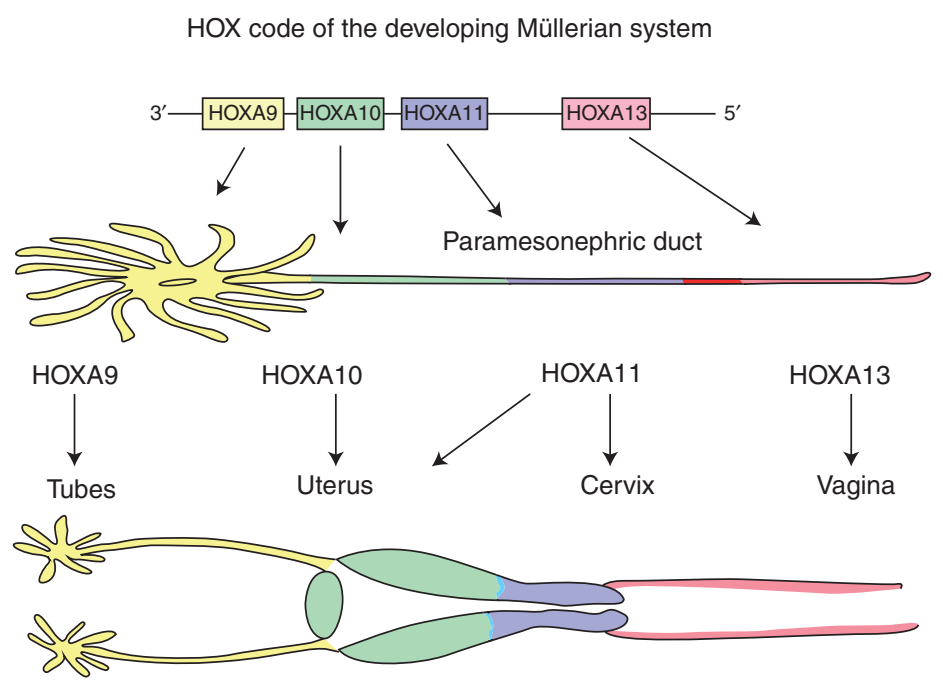

Figure 1. HOX code of the developing Müllerian system (adapted from Taylor 2000).

1997, 1998, 1999b). Persistent HOX gene expression in the adult may be a mechanism to retain developmental plasticity in the female reproductive tract.

Emx2 is a divergent Homeobox gene, which is a mammalian homolog of the Drosophila empty spiracles (ems) gene. The vertebrate Emx2 gene is located outside of the Hox cluster, and is expressed in the developing vertebrate brain as well as the urogenital system (Simeone et al. 1992a,b). In the embryo, Emx2 is expressed in the epithelial components of the pronephros, mesonephros, ureteric buds, and the Wolffian and Müllerian ducts. In mouse embryos, Emx2 expression is greatly diminished in male gonad, but strong expression remains detectable throughout the female gonad. Null mutants of Emx2 mice fail to develop kidneys, gonads or a reproductive tract (Pellegrini et al. 1997; Svingen and Koopman 2007). In adults, EMX2 has been detected in the human uterus. The expression of EMX2 displayed a dynamic pattern that varied with the developmental phase of the human reproductive cycle (Fig. 2) (Troy et al. 2003).

\section{The Role of HOX Genes in Female Fertility}

Female fertility is a broad term, which includes the ability to reproduce or become pregnant.
Multiple factors influence female fertility, including normal aging and several disease processes. However, two processes are essential for normal female fertility: ovarian follicular maturation and embryo implantation. In vertebrates, HOX genes are involved in both of these processes.

Ovarian follicle development is a complex process in which many transcription factors participate. As described above, HOX genes containing the evolutionarily conserved HD sequence encode a family of DNA-binding transcription factors whose functions are crucial for embryonic development in vertebrates. In 1995, HOXA4 and HOXA7 expression was first described in the human unfertilized oocytes (Verlinsky et al. 1995). Sequence analysis of cDNA libraries generated from human unfertilized oocytes confirmed the expression of HOXA7 (Adjaye and Monk 2000). Furthermore, in human ovarian folliculogenesis, HOXA7 expression is nearly absent in primordial follicles but high in primary and mature follicles. During follicular maturation, the subcellular localization of HOXA7 changes from nuclear to predominantly cytoplasmic. This differential localization indicates that HOXA7 undergoes cell type- and stage-specific changes during the human ovarian folliculogenesis, and regulates proliferative 


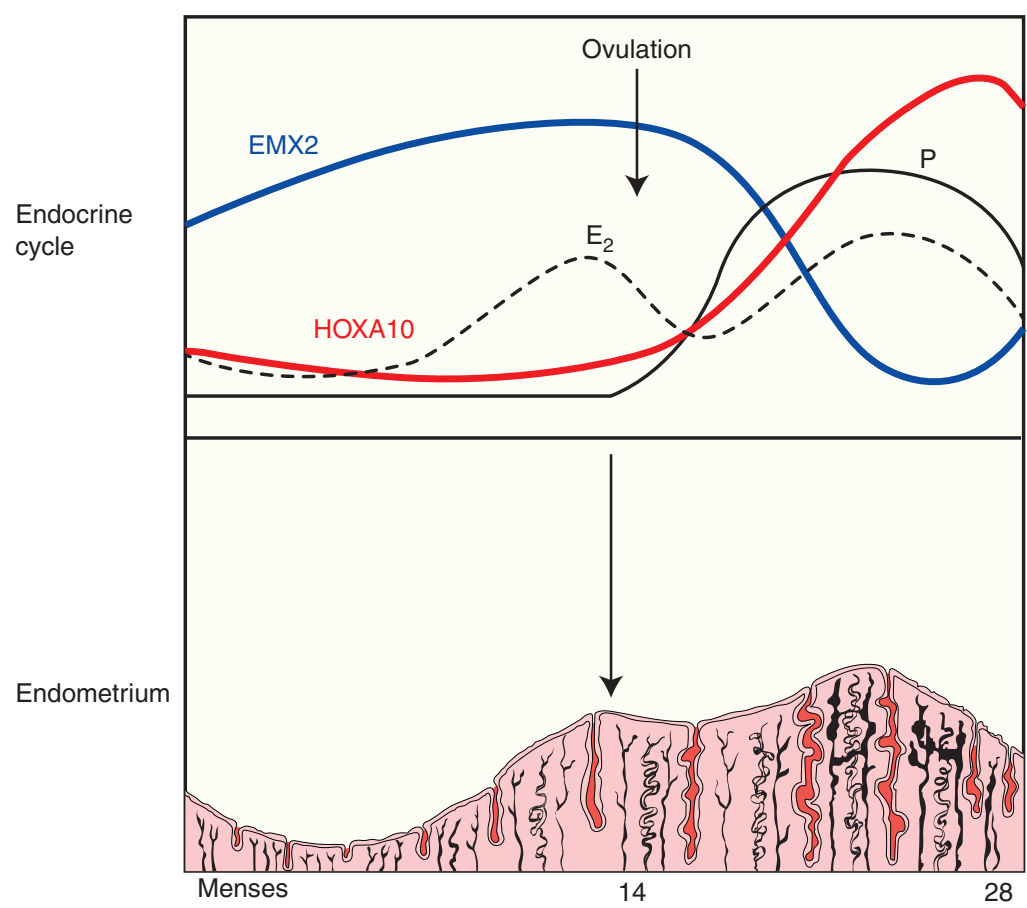

Figure 2. The pattern of HOXA10 expression in the human endometrium through the menstrual cycle (adapted from Taylor 2000). HOXA11 expression closely parallels that of HOXA10.

activities of ovarian follicles (Ota et al. 2006). Granulosa cells surround the developing oocyte, providing a critical microenvironment for follicular growth. During this process, the oocyte and the granulosa cells establish mutual interactions and their growth is regulated by coordinated paracrine mechanisms. HOXA7 modulates granulosa cell growth and proliferation not only via the regulation of the epidermal growth factor receptor (EGFR), but also forms dimers with the $H O X$ gene cofactor pre-B-cell leukemia transcription factor 2 (PBX2) to bind the specific promoter regions in the human granulosa cells. HOXA7 plays an important role in ovarian follicular maturation (Ota et al. 2008; Zhang et al. 2010).

Embryo implantation is critical for female reproduction. This process is a complex event requiring synchronization between a developing embryo and receptive endometrium. Fundamental to this process is the dynamic and precisely ordered molecular and cellular events that drive and stabilize the interaction between the developing embryo and its host endometrium. As described above, Hoxa10/HOXA10 and Hoxa11/HOXA11 are expressed in endometrial glands and stroma throughout the estrus/menstrual cycle. These two HOX genes are essential for embryo implantation in both mice and humans (Hsieh-Li et al. 1995; Satokata et al. 1995; Benson et al. 1996; Gendron et al. 1997). Targeted mutation of either Hoxa10 or Hoxa11 in the mice leads to infertility related to defects in uterine receptivity. Embryos produced by Hoxa10 deficient mice are viable and can successfully implant in wild-type surrogates. However, those embryos are not able to implant or survive in the uteri of Hox gene knockout mice. Although the uteri of these knockout mice appear anatomically normal, they do not support the development or implantation of their own embryos, nor of embryos from the wild-type mice. Histologic abnormalities were noted in the Hoxa10 deficient mice, resulting in a homeotic transformation of the anterior part of the uterus into an oviduct-like structure. Similarly, 
the mice with a homozygous mutation in the Hoxa11 gene are infertile because of implantation defects. Those mice have reduced endometrial glands and decreased leukemia inhibitory factor (LIF) secretion. Targeted mutation of orthologous Hox genes such as both Hoxd9 and Hoxd10 in mice does not result in abnormalities on uterine structure or position (De La Cruz et al. 1999). Although no human females with mutations in HOXA10 and HOXA11 have been described, it has been reported that patients with lower implantation rates have lower HOXA10 and HOXA11 expression in the secretory phase, which indicates that maternal $H O X$ gene expression is conserved and necessary for endometrial receptivity (Taylor et al. 1999b; Bagot et al. 2000; Taylor 2000).

Estrogens and Progesterone

Regulate Hox Gene Expression in the Reproductive Tract

So far, few regulators of $H O X$ gene expression have been identified. Sex steroids have been investigated in the regulation of the HOX genes at the $5^{\prime}$ end of the cluster, which determine the posterior development, including the development of female reproductive tract (Taylor et al. 1997, 1998, 1999b; Ma et al. 1998; Cermik et al. 2001; Goodman 2002). During each reproductive cycle, endometrial epithelial and stromal cells display a well-defined cyclic pattern of functional differentiation under the influence of estrogen and progesterone. Menstrual cyclicity is regulated by timed expression of estrogen and progesterone, which act both independently and in concert to up-regulate HOXA10 and HOXA11 expression in the endometrium. In normal cycling women, HOXA10 and HOXA11 levels increase, reaching maximal expression during the mid-secretory phase, and remaining elevated throughout the secretory phase. In endometrial stromal cells, $17 \beta$-estradiol and progesterone significantly increase HOXA10 and HOXA11 expression. HOXA9 is under the control of both estrogen and progesterone as well. The regulation of HOX gene expression in the adult uterus by ovarian steroids is related to its position within the cluster and mediated by the direct action of estrogen and progesterone receptors on these genes.

Humans are exposed to a wide variety of chemicals that have estrogenic properties. Those estrogenic compounds show profound and lasting effects on essential developmental genes in female reproductive tract. They have potential to alter the expression of estrogen responsive genes, such as HOX genes. These changes are likely to influence reproductive competence. Diethylstilbestrol (DES) is a nonsteroidal estrogen, a well-known teratogen. This chemical alters the localization of Hox gene expression along the axis of the developing murine reproductive tract, and induces developmental anomalies of female reproductive tract (Ma et al. 1998; Akbas et al. 2004). DES exposure in utero shifts Hoxa9 expression from the oviducts to the uterus and leads to decreases in both Hoxa10 and Hoxa11 expression in the uterus. The decreased expression of the Hoxa genes may cause a "Tshaped" uterus, a structure that is characterized by branching and narrowing of the uterus into a tube-like phenotype. This phenotype is likely caused by expression of the Hox gene that controls tubal identity (Hoxa9) ectopically in the uterus. Because the multiple $H O X$ gene clusters provide an overlapping expression pattern in the mice and humans, the complete transformation into an oviduct is probably prevented.

Studies on xenoestrogens, such as methoxychlor (MXC) and bisphenoyl A (BPA), have shown that exposure to these chemicals also alters the Hoxa10 expression in female reproductive tract (Block et al. 2000; Suzuki et al. 2004; Fei et al. 2005; Markey et al. 2005; Sugiura-Ogasawara et al. 2005; Daftary and Taylor 2006; Smith and Taylor 2007). MXC is a pesticide and this chemical is associated with female reproductive defects after either prenatal or postnatal exposure. MXC specifically alters Hoxa10 gene expression, specifically the Hoxal0 gene expression. This HOX gene is responsible for normal uterine development and fertility, and its expression is permanently repressed in the uterus of mice exposed to MXC in utero. This effect is mediated through the HOXA10 estrogen response element (ERE) in a dose-dependent pattern. 
BPA, another xenoestrogen, is a common component of polycarbonate plastics, epoxies used in food storage, canned goods, and dental sealants. BPA is also associated with adverse reproductive outcomes in both animal models and humans. After exposure to BPA in utero, Hoxa10 expression is increased in female mice and this altered expression persisted in adults. The alternation of the gene expression persists long after exposure and alters the normally precise, temporal regulation of Hoxa10 in reproductive tract development. This permanently modified expression of Hoxa10 contributes to the decline in female reproductive potential. Despite its opposite effect on $H O X$ gene expression in vivo, BPA behaves similarly to MXC in vitro by stimulating the HOXA10 ERE. The difference seen after in utero exposure likely represents the unique molecular signals present in the embryo and underlies the increased risk of exposure to environmental chemicals during critical periods of development. Exposure to various xenoestrogens alters Hoxa10 gene expression in the developing reproductive tract, and these exposures may lead to permanent alteration of gene expression in the adult (Fig. 3) (Taylor 2008).

\section{HOX GENES AND INFERTILITY}

HOX genes are essential for endometrial development and embryo implantation in both mice and humans. As described above, the association between alteration of Hoxa gene expression and fertility is evident in animal models (Fig. 4) (Paria et al. 2002). The Hoxa10/HOXA10 and Hoxa11/HOXA11 genes act as important transcriptional moderators that either activate or repress the downstream target genes; these targets include $\beta 3$-integrin and Emx2/EMX2, which are themselves important for embryo implantation. As discussed earlier, in normal cycling women, there is a surge of HOXA10 and HOXA11 expression during the mid-secretory phase; diminished HOXA10 and HOXA11 expression in the secretory phase leads to low embryo implantation rates. Impaired uterine receptivity has been studied in several gynecological diseases that lead to infertility. These include endometriosis, polycystic ovarian syn- drome, leiomyoma, and hydrosalpinx. Compared with controls, there is diminished HOXA10 and HOXA11 expression in woman with each of those disorders (discussed in detail below). Although differential mechanisms may lead to decreased expression, it appears that altered HOX gene expression is so central to the process of implantation that decrease of their expression is required to diminish implantation. Alterations in the expression of $H O X$ genes cause infertility in humans primarily by endometrial receptivity defects and impaired implantation.

\section{HOX Genes and Endometriosis}

Endometriosis is an estrogen-dependent benign inflammatory disease defined by the presence of viable endometrial tissue outside the uterine cavity. The prevalence of endometriosis has been estimated as up to $10 \%$ to $15 \%$ of reproductive-age women and $30 \%-50 \%$ of women with endometriosis have infertility (Verkauf 1987; Olive and Pritts 2001). Multiple factors are considered to contribute to endometriosis related infertility, including altered folliculogenesis, impaired fertilization, poor oocyte quality, and defective implantation. Here, we will focus on the role of diminished implantation as it is related to diminished $H O X$ gene expression. In patients with endometriosis, implantation rates are reduced during both natural and assisted reproductive technology cycles, even in patients with minimal disease (Barnhart et al. 2002). Two of the HOXA genes, HOXA10 and HOXA11, involved in uterine embryogenesis and endometrial receptivity, have been implicated in the pathogenesis of endometriosisassociated infertility. In humans, the expression of both HOXA10 and HOXA11 rises dramatically during the implantation window and remains elevated throughout the secretory phase. However, patients with endometriosis do not show this rise in HOXA10 and HOXA11 (Taylor et al. 1999a; Kim et al. 2007; Lee et al. 2009).

HOXA10 downstream target genes are also involved in this pathologic mechanism. As discussed above, EMX2 is a divergent Homeobox gene, cyclically expressed in the adult 
H. Du and H.S. Taylor

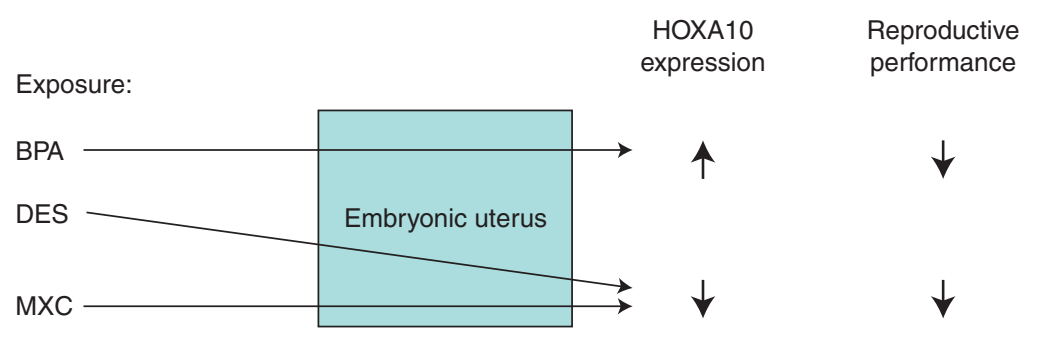

Figure 3. Exposure to various xenoestrogens alters HOXA10 gene expression in the developing reproductive tract. BPA, bisphenol A; DES, diethylstilbestrol; and MXC, methoxychlor.

endometrium. Endometrial EMX2 expression is directly regulated by endogenous endometrial HOXA10. Normally EMX2 expression is downregulated in the peri-implantation period; however, this regulated expression fails in women with endometriosis (Troy et al. 2003; Daftary and Taylor 2004). Further demonstrating the important role of this target gene, altering the endometrial Emx2 levels is not only associated with defective implantation, but also reduces litter size in mice (Taylor and Fei 2005). Aberrant endometrial EMX2 expression in women with endometriosis is mediated by altered HOXA10 expression.

Furthermore, another biomarker of endometrial receptivity to embryonic implantation is also found to be decreased in endometriosis. Integrins are ubiquitous cell adhesion molecules that participate in cell-cell and cell-substratum interactions. These molecules undergo dynamic alterations during the normal menstrual cycle in the human endometrium. $\beta 3$ integrin is expressed in endometrium at the time of implantation, and the disruption of in-

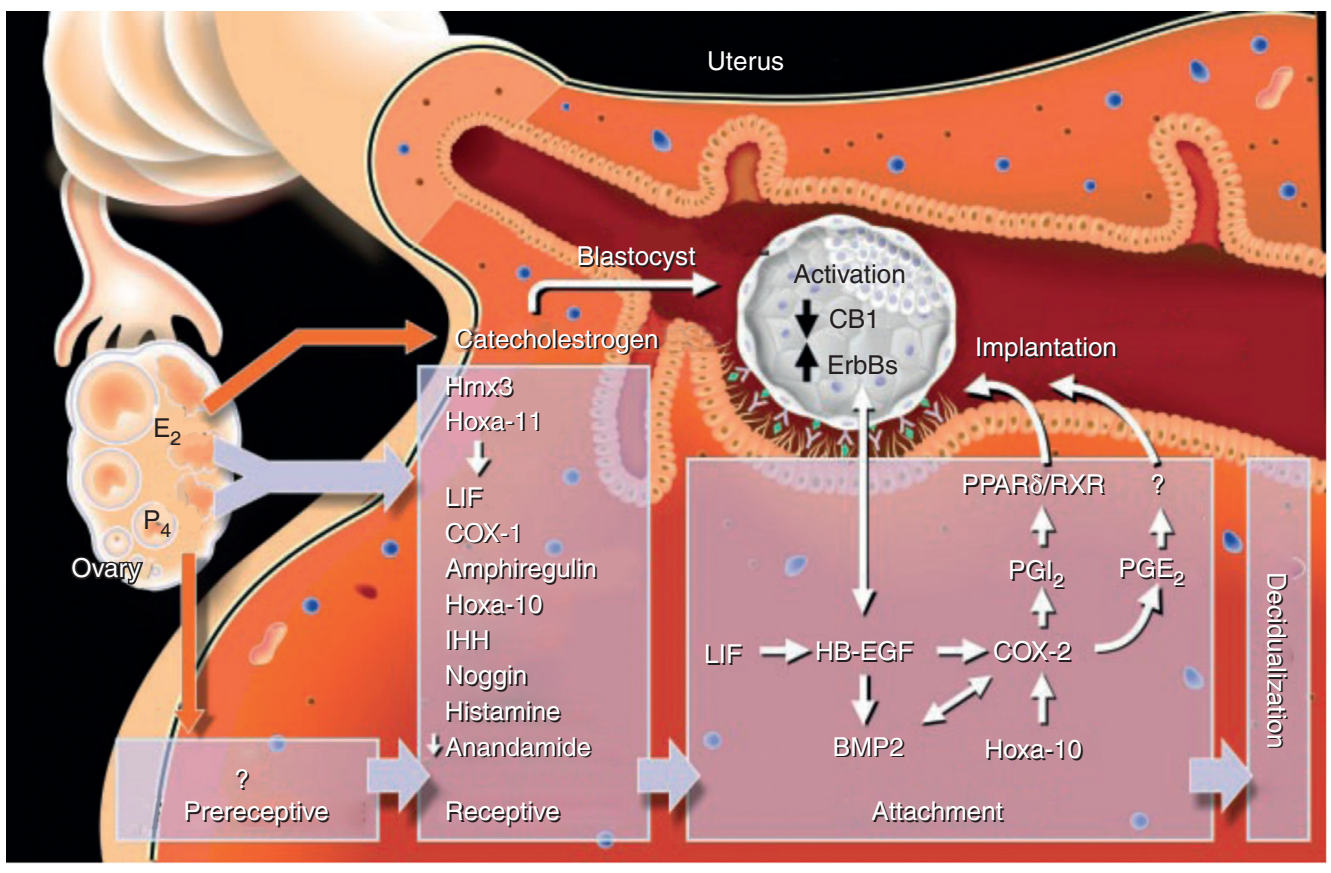

Figure 4. Molecular signaling during implantation in the mouse and human. (From Paria et al. 2002, reprinted, with permission, from The American Association for the Advancement of Science (C)2002.) 
Hox Genes and Female Reproduction

tegrin expression is associated with decreased uterine receptivity and infertility (Lessey and Young 1997). Interestingly, $\beta 3$-integrin subunit is a direct Hoxa10 downstream target gene, and directly regulated by HOXA10 in endometrial cells. Aberrant expression of both HOXA10 and integrins have been described in the endometrium of women with endometriosis (Lessey et al. 1994; Lessey and Young 1997; Daftary et al. 2002; Klemmt et al. 2006; Cakmak and Taylor 2011).

Recent studies indicate that epigenetic modifications may play an important role in pathological process in endometriosis. Epigenetics refers to heritable alteration of DNA by longlasting covalent methyl modification without DNA sequence changes. These epigenetic changes have been described in numerous studies including hypermethylation of HOXA10, progesterone receptor- $\beta$, and E-cadherin or hypomethylation of genes for estrogen receptor- $\beta$ and steroidogenic factor 1 (Guo 2009; Senapati and Barnhart 2011). In both murine and baboon endometriosis models, hypermethylation of the promoter region of Hoxa10/HOXA10 and decreased expression of Hoxa10/HOXA10 genes were shown in eutopic endometrium (Kim et al. 2007; Lee et al. 2009). In humans, hypermethylation of HOXA10 was identified in the endometrium of women with endometriosis (Wu et al. 2005). The DNA methyltransferase (DNMT) is a family of enzymes, which catalyze the transfer of a methyl group to DNA. DNMT 1, 3A, and 3B were found to be overexpressed in the epithelial component of endometriotic implants. However, only DNMT3A was found to be up-regulated in eutopic endometrium of women with endometriosis ( $\mathrm{Wu}$ et al. 2007). A recently published study, using a genome-wide methylation array, shows that HOXA10 expression was repressed and methylation of HOXA10 gene was altered by 1.3 -fold in human endometriosis (Naqvi et al. 2014). Other HOX genes, such as HOXD10 and HOXD11, also showed significantly altered methylation in endometriosis (Naqvi et al. 2014). Epigenetic programming of HOX gene expression in endometriosis leads to lasting alterations in endometrial receptivity.

\section{HOX Genes and Polycystic Ovarian Syndrome}

Polycystic ovarian syndrome (PCOS) is a common endocrine disease, afflicting 5\% of women of reproductive age. It is characterized by anovulation and elevated androgen action. Infertility associated with PCOS derives from chronic anovulation. Despite the ability to correct ovulatory disorders, pregnancy rates remain paradoxically low, and spontaneous pregnancy loss rates are high. In women with PCOS, between $30 \%$ and $50 \%$ of all conceptions miscarry (Giudice 2006). Some data also suggest that poor oocyte quality, implantation failure, and higher rates of miscarriage further complicate achieving and maintaining a pregnancy in women with this disorder. Women with PCOS are also at significantly higher risk of endometrial hyperplasia (Niwa et al. 2000). PCOS may have complex effects on the endometrium, contributing to the infertility. Furthermore, increasing evidence and emerging data have shown that endometrial receptivity contributes to the infertility of PCOS even in the setting of ovulation induction (Giudice 2006). An increase in the expression of HOXA10 in the endometrium is necessary for receptivity to embryo implantation. However, endometrial biopsies obtained from women with PCOS in ovulatory cycles have shown that HOXA10 expression is decreased compared with normal fertile women during the secretory phase (Cermik et al. 2003). In vitro, HOXA10 expression is repressed by testosterone (Cermik et al. 2003). Testosterone also prevents the increased expression of HOXA10 induced by estradiol or progesterone. Dihydrotestosterone produced an effect similar to that of testosterone, whereas flutamide blocked the testosterone effect. Diminished uterine HOXA10 expression may contribute to the diminished reproduction potential of women with PCOS, illustrating a significant effect of the disease on receptivity. Elevated androgen levels may induce infertility associated with PCOS by altering HOX gene expression.

As discussed above, $\beta 3$-integrin, a biomarker of endometrial receptivity to embryonic implantation, is a $H O X$ target gene that is 
directly regulated by HOXA10 in endometrial cells. The expression of this biomarker is decreased in endometrium from women with PCOS compared with fertile controls (Apparao et al. 2002). Also, as described above, after ovulation induction treatment of infertility in PCOS, implantation rates remain low. In fertile women, when ovulation is induced with clomiphene citrate, the treatment provokes the expression of endometrial integrins at the implantation window. Interestingly, integrin is decreased in endometrial biopsy specimens from women with PCOS even after clomiphene citrate treatment (Gonzalez et al. 2001; Jakubowicz et al. 2001).

\section{HOX Genes and Leiomyoma}

Leiomyomas (fibroids) are the most common benign uterine tumor of reproductive age women. The growth of leiomyoma is strictly related to sex steroids and their receptors. Their presence is associated with menorrhagia and poor reproductive outcomes. The prevalence of uterine fibroids approaches to $33 \%$ of women of reproductive age based on clinical assessment, and up to $50 \%$ on ultrasound scans. This disorder presents in $5 \%-10 \%$ of women with infertility (Payson et al. 2006; Revel 2012).

The presence of a distorted uterine cavity caused by leiomyomas significantly decreases in vitro fertilization (IVF) pregnancy rates. Fortunately, myomectomy can increase the pregnancy rates in patients with leiomyoma-related infertility (Bulletti et al. 1999; Surrey et al. 2001). However, the mechanisms by which leiomyoma cause infertility are not fully known. HOXA10 is expressed in human myometrium and its expression also has a menstrual cycledependent pattern. In vitro, HOXA10 expression is induced in endometrial stromal cells by progesterone, but in the primary myometrial cells, progesterone suppresses HOXA10 expression (Cermik et al. 2001; Matsuzaki et al. 2009; Rackow and Taylor 2010; Sinclair et al. 2011). It is clear that there are different factors involved in the regulation of HOXA10 by progesterone in myometrium than endometrium. Further, independent of any change in progesterone con- centration, endometrial HOXA10 and HOXA11 expression are significantly decreased in uteri with submucosal myomas compared with controls. This effect is not localized to the endometrium overlying the myoma; rather the decreased HOXA10 expression is seen throughout the endometrium. This global effect of the myoma on endometrium suggests the presence of a diffusible factor that would influence endometrial receptivity remote from the myoma itself. Indeed, we have recently reported that TGF $\beta$ secreted by myomas leads to decreased BMP receptor expression and subsequent HOXA10 repression (Sinclair et al. 2011). Leiomyoma alter endometrial receptivity by secreting TGF $\beta$ and altering genes including HOXA10 that are required for implantation.

\section{HOX Genes and Hydrosalpinx}

Hydrosalpinx is an inflammatory disease involving the oviduct. The prevalence of hydrosalpinges in patients suffering from tubal disease is relatively common and ranges from 10\% to $13 \%$ when diagnosed by ultrasound, and up to $30 \%$ when diagnosed by hysterosalpingography or at the time of surgery (Cakmak and Taylor 2011). Women with hydrosalpinges have decreased implantation rates in IVF, and their pregnancy rates can be improved with salpingectomy before IVF. The hydrosalpinx generates an inflammatory fluid that may interfere with endometrial receptivity and embryonic implantation mechanically or chemically (Zeyneloglu et al. 1998; Camus et al. 1999). Although a study has shown that culturing mice embryos in the medium containing hydrosalpinx fluid can suppress embryo maturation and promote degeneration, this toxic effect does not affect human embryos. (Mukherjee et al. 1996; Strandell et al. 1998) We performed an in vitro study demonstrating that hydrosalpinx fluid decreased endometrial HOXA10 mRNA expression in a dose-dependent pattern. Subsequently, studies on women with hydrosalpinges show that the expression of HOXA10 was significantly lower in women with hydrosalpinges compared with fertile controls. After salpingectomy, HOXA10 expression in infertile women with hydrosal- 
pinges was similar to that of age-matched fertile women, indicating that salpingectomy restores HOXA10 expression to physiological levels (Daftary and Taylor 2002; Daftary et al. 2007).

As described above, $\beta 3$-integrin subunit is a well-characterized endometrial receptivity marker, directly regulated by HOXA10 in endometrial cells. In women with the presence of hydrosalpinges, the expression of $\beta 3$-integrin is also reduced. Interestingly, two thirds of patients with hydrosalpinx who underwent salpingectomy also showed return of HOXA10 and $\beta 3$-integrin back to normal levels (Bildirici et al. 2001).

\section{SUMMARY}

All metazoans use $H O X$ genes to regulate embryonic patterning. HOX genes play a fundamental role in morphogenesis during embryonic development. Well-characterized examples include the role of $\mathrm{HOX}$ genes in the patterning of the vertebrate hindbrain, skeleton, and limbs. In reproduction, HOX genes determine positional identity during embryonic development of the female reproductive tract. Abnormalities in reproductive tract development are related to $H O X$ gene mutations and to alterations in the normal HOX gene expression patterns. This has been clearly shown in mice with targeted Hox gene mutations as well as in mice exposed to chemicals with estrogenic properties such as DES. In the adult, the endometrium undergoes an ordered process of differentiation leading to receptivity to implantation. $H O X$ genes are also essential to this process. As transcription factors, HOX genes control cyclical endometrial development and receptivity by activating or repressing the expression of target genes. HOXA10 and HOXA11 expression increases drastically in the mid-secretory phase, the time of implantation, and they remain elevated throughout the secretory phase. This increased expression is necessary for embryonic implantation; decreased Hoxa10/HOXA10 and Hoxa11/HOXA11 expression at this time leads to decrease implantation rates in both mice and humans. Impaired uterine receptivity has been studied in several infertility-related gynecolog- ical diseases, such as endometriosis, polycystic ovarian syndrome, leiomyoma, and hydrosalpinx. Alternation of HOXA10 and HOXA11 expression has been identified as a mechanism of the decreased implantation associated with these disorders. Alteration of Hoxa gene expression causes both uterine developmental abnormalities and impaired adult endometrial development that prevent implantation and lead to female infertility.

\section{REFERENCES}

Adjaye J, Monk M. 2000. Transcription of homeobox-containing genes detected in cDNA libraries derived from human unfertilizedoocytes and preimplantation embryos. Mol Hum Reprod 6: 707-711.

Akbas GE, Song J, Taylor HS. 2004. A HOXA10 estrogen response element (ERE) is differentially regulated by 17 $\beta$-estradiol and diethylstilbestrol (DES). J Mol Biol 23: 1013-1023.

Apparao KB, Lovely LP, Gui Y, Lininger RA, Lessey BA. 2002. Elevated endometrial androgen receptor expression in women with polycystic ovarian syndrome. Biol Reprod 66: $297-304$.

Bagot CN, Troy PJ, Taylor HS. 2000. Alteration of maternal Hoxa10 expression by in vivo gene transfection affects implantation. Gene Ther 7: 1378-1384.

Barnhart K, Dunsmoor-Su R, Coutifaris C. 2002. Effect of endometriosis on in vitro fertilization. Fertil Steril 77: $1148-1155$.

Benson GV, Lim H, Paria BC, Satokata I, Dey SK, Maas RL. 1996. Mechanisms of reduced fertility in Hoxa-10 mutant mice: Uterine homeosis and loss of maternal Hoxa10 expression. Development 122: 2687-2696.

Bildirici I, Bukulmez O, Ensari A, Yarali H, Gurgan T. 2001. A prospective evaluation of the effect of salpingectomy on endometrial receptivity in cases of women with communicating hydrosalpinges. Hum Reprod 16: 2422 2426.

Block K, Kardana A, Igarashi P, Taylor HS. 2000. In utero diethylstilbestrol (DES), exposure alters Hox gene expression in the developing Müllerian system. FASEB J 14: $1101-1108$

Bulletti C, De Ziegler D, Polli V, Flamigni C. 1999. The role of leiomyomas in infertility. J Am Assoc Gynecol Laparosc 6: $441-445$.

Cakmak H, Taylor HS. 2011. Implantation failure: Molecular mechanisms and clinical treatment. Hum Reprod Update 17: 242-253.

Camus E, Poncelet C, Goffinet F, Wainer B, Merlet F, Nisand I, Philippe HJ. 1999. Pregnancy rates after in-vitro fertilization in cases of tubal infertility with and without hydrosalpinx: A meta-analysis of published comparative studies. Hum Reprod 14: 1243-1249.

Carpenter EM, Goddard JM, Chisaka O, Manley NR, Gapecchi MR. 1993. Loss of Hox-A1 (Hox-1.6) function 
H. Du and H.S. Taylor

results in the reorganization of the murine hindbrain. Development 118: 1063-1075.

Cermik D, Karaca M, Taylor HS. 2001. HOXA10 expression is repressed by progesterone in the myometrium: Differential tissue-specific regulation of $H O X$ gene expression in the reproductive tract. J Clin Endocrinol Metab 86: 3387-3392.

Cermik D, Selam B, Taylor HS. 2003. Regulation of HOXA10 expression by testosterone in vitro and in the endometrium of patients with polycystic ovary syndrome. J Clin Endocrinol Metab 88: 238-243.

Daftary GS, Taylor HS. 2002. Hydrosalpinx fluid diminishes endometrial cell HOXA10 expression. Fertil Steril 78: 577-580.

Daftary GS, Taylor HS. 2004. EMX2 gene expression in the female reproductive tract and aberrant expression in the endometrium of patients with endometriosis. J Clin Endocrinol Metab 89: 2390-2396.

Daftary GS, Taylor HS. 2006. Endocrine regulation of Hox genes. Endocr Rev 27: 331-335.

Daftary GS, Troy PJ, Bagot CN, Young SL, Taylor HS. 2002. Direct regulation of $\beta 3$-integrin subunit gene expression by HOXA10 in endometrial cells. Mol Endocrinol 16: 571-579.

Daftary GS, Kayisli U, Seli E, Bukulmez O, Arici A, Taylor HS. 2007. Salpingectomy increases peri-implantation endometrial HOXA10 expression in women with hydrosalpinx. Fertil Steril 87: 367-372.

Davis AP, Capecchi MR. 1996. A mutational analysis of the $5^{\prime}$ HoxD genes: Dissection of genetic interactions during limb development in the mouse. Development 122: 1175-1185.

De La Cruz CC, Der-Avakian A, Spyropoulos DD, Tieu DD, Carpenter EM. 1999. Targeted disruption of Hoxd 9 and Hoxd10 alters locomotor behavior, vertebral identity, and peripheral nervous system development. Dev Biol 216: 595-610.

Dolle P, Izpisua-Belmonte JC, Brown JM, Tickle C, Duboule D. 1991. HOX-4 genes and the morphogenesis of mammalian genitalia. Genes Dev 5: 1767-1776.

Favier B, Dolle P. 1997. Developmental functions of mammalian Hox genes. Mol Hum Reprod 3: 115-131.

Fei X, Chung H, Taylor HS. 2005. Methoxychlor disrupts uterine Hoxal0 gene expression. Endocrinology 146: 3445-3451.

Ferretti E, Marshall H, Popperl H, Maconochie M, Krumlauf R, Blasi F. 2000. Segmental expression of Hoxb2 in r4 requires two separate sites that integrate cooperative interactions between Prep1, Pbx and Hox proteins. Development 127: 155-166.

Fromental-Ramain C, Warot X, Lakkaraju S, Favier B, Haack H, Birling C, Dierich A, Dolle P, Chambon P. 1996. Specific and redundant functions of the paralogous Hoxa-9 and Hoxd-9 genes in forelimb and axial skeleton patterning. Development 122: 461-472.

Gehring WJ, Affolter M, Burglin T. 1994. Homeodomain proteins. Annu Rev Biochem 63: 487-526.

Gendron RL, Paradis H, Hsieh-Li HM, Lee DW, Potter SS, Markoff E. 1997. Abnormal uterine stromal and glandular function associated with maternal reproductive defects in Hoxa-11 null mice. Biol Reprod 56: 1097-1105.
Giudice LC. 2006. Endometrium in PCOS: Implantation and predisposition to endocrine CA. Best Pract Res Clin Endocrinol Metab 20: 235-244.

Goddard JM, Rossel M, Manley NR, Capecchi MR. 1996. Mice with targeted disruption of Hoxb-1 fail to form the motor nucleus of the VIIth nerve. Development 122: 3217-3228.

Goff DJ, Tabin CJ. 1997. Analysis of Hoxd-13 and Hoxd-11 misexpression in chick limb buds reveals that Hox genes affect both bone condensation and growth. Development 124: $627-636$.

Gonzalez RR, Palomino A, Vantman D, Gabler F, Devoto L. 2001. Abnormal pattern of integrin expression at the implantation window in endometrium from fertile women treated with clomiphene citrate and users of intrauterine device. Early Pregnancy 5: 132-143.

Goodman FR. 2002. Limb malformations and the human HOX genes. Am J Med Genet 112: 256-265.

Gruschus JM, Tsao DH, Wang LH, Nirenberg M, Ferretti JA. 1999. The three-dimensional structure of the vnd/NK-2 homeodomain-DNA complex by NMR spectroscopy. $J$ Mol Biol 289: 529-545.

Guo SW. 2009. Epigenetics of endometriosis. Mol Hum Reprod 15: 87-607.

Horan GS, Ramirez-Solis R, Featherstone MS, Wolgemuth DJ, Bradley A, Behringer RR. 1995. Compound mutants for the paralogous hoxa-4, hoxb-4, and hoxd-4 genes show more complete homeotic transformations and a dose-dependent increase in the number of vertebrae transformed. Genes Dev 9: 1667-1677.

Hsieh-Li HM, Witte DP, Weinstein M, Brandford W, Li H, Small K, Potter SS. 1995. Hoxa 11 structure, extensive antisense transcription, and function in male and female fertility. Development 121: 1373-1385.

Hunt P, Krumlauf R. 1992. Hox codes and positional specification in vertebrate embryonic axes. Annu Rev Cell Biol 8: $227-256$.

Jakubowicz DJ, Seppälä M, Jakubowicz S, Rodriguez-Armas O, Rivas-Santiago A, Koistinen H, Koistinen R, Nestler JE. 2001. Insulin reduction with metformin increases luteal phase serum glycodelin and insulin-like growth factor-binding protein 1 concentrations and enhances uterine vascularity and blood flow in the polycystic ovary syndrome. J Clin Endocrinol Metab 86: 1126-1133.

Kim JJ, Taylor HS, Lu Z, Ladhani O, Hastings JM, Jackson KS, Wu Y, Guo SW, Fazleabas AT. 2007. Altered expression of HOXA10 in endometriosis: Potential role in decidualization. Mol Hum Reprod 13: 323-332.

Klemmt PA, Carver JG, Kennedy SH, Koninckx PR, Mardon HJ. 2006. Stromal cells from endometriotic lesions and endometrium from women with endometriosis have reduced decidualization capacity. Fertil Steril 85: 564-572.

Krumlauf R. 1994. Hox genes in vertebrate development. Cell 78: 191-201.

Lee B, Du H, Taylor HS. 2009. Experimental murine endometriosis induces DNA methylation and altered gene expression in eutopic endometrium. Biol Reprod 80: 79-85.

Lessey BA, Young SL. 1997. Integrins and other cell adhesion molecules in endometrium and endometriosis. Semin Reprod Endocrinol 15: 291-299. 
Lessey BA, Castelbaum AJ, Sawin SW, Buck CA, Schinnar R, Bilker W, Strom BL. 1994. Aberrant integrin expression in the endometrium of women with endometriosis. J Clin Endocrinol Metab 79: 643-649.

Lewis EB. 1978. A gene complex controlling segmentation in Drosophila. Nature 276: 565-570.

Ma L, Benson GV, Lim H, Dey SK, Maas RL. 1998. Abdominal $B(A b d B)$ Hoxa genes: Regulation in adult uterus by estrogen and progesterone and repression in Müllerian duct by the synthetic estrogen diethylstilbestrol (DES) Dev Biol 197: 141-154.

Manzanares M, Cordes S, Ariza-McNaughton L, Sadl V, Maruthainar K, Barsh G, Krumlauf R. 1999. Conserved and distinct roles of kreisler in regulation of the paralogous Hoxa3 and Hoxb3 genes. Development 126: 759769.

Mark M, Lufkin T, Vonesch JL, Ruberte E, Olivo JC, Dolle P, Gorry P, Lumsden A, Chambon P. 1993. Two rhombomeres are altered in Hoxa-1 mutant mice. Development 119: $319-338$.

Markey CM, Wadia PR, Rubin BS, Sonnenschein C, Soto AM. 2005. Longterm effects of fetal exposure to low doses of the xenoestrogenbisphenol-A in the female mouse genital tract. Biol Reprod 72: 1344-1351.

Matsuzaki S, Canis M, Darcha C, Pouly JL, Mage G. 2009. HOXA-10 expression in the mid-secretory endometrium of infertile patients with either endometriosis, uterine fibromas or unexplained infertility. Hum Reprod 24: 3180-3187.

McGinnis W, Krumlauf R. 1992. Homeobox genes and axial patterning. Cell 68: 283-302.

McGinnis W, Garber RL, Wirz J, Gehring WJ. 1984a. A homologous protein-coding sequence in Drosophila homeotic genes and its conservation in other metazoans. Cell 37: 403-408.

McGinnis W, Levine MS, Hafen E, Kuroiwa A, Gehring WJ. 1984b. A conserved DNA sequence in homeotic genes of the Drosophila antennapedia and bithorax complexes. Nature 308: 428-433.

Morrison A, Ariza-McNaughton L, Gould A, Featherstone M, Krumlauf R. 1997. HOXD4 and regulation of the group 4 paralog genes. Development 124: 3135-3146.

Mukherjee T, Copperman AB, McCaffrey C, Cook CA, Bustillo M, Obasaju MF. 1996. Hydrosalpinx fluid has embryotoxic effects on murine embryogenesis: A case for prophylactic salpingectomy. Fertil Steril 66: 851-853.

Muragaki Y, Uragaki S, Upton J, Olsen BR. 1996. Altered growth and branching patterns in synpolydactyly caused by mutations in HOXD13. Science 272: 548-551.

Naqvi HI, Ilagan Y, Krikun G, Taylor HS. 2014. Altered genome-wide methylation in endometriosis. Reprod Sci 21: 1237-1243.

Nelson CE, Morgan BA, Burke AC, Laufer E, DiMambro E, Murtaugh LC, Gonzales E, Tessarollo L, Parada LF, Tabin C. 1996. Analysis of Hox gene expression in the chick limb bud. Development 122: 1449-1466.

Niwa K, Imai A, Hashimoto M, Yokoyama Y, Mori H, Matsuda Y, Tamaya T. 2000. A case-control study of uterine endometrial cancer of pre- and postmenopausal women. Oncol Rep 7: 89-93.
Olive DL, Pritts EA. 2001. Treatment of endometriosis. $N$ Engl J Med 345: 266-275.

Ota T, Choi KB, Gilks CB, Leung PC, Auersperg N. 2006. Cell type- and stage-specific changes in HOXA7 protein expression in human ovarian folliculogenesis: Possible role of GDF-9. Differentiation 74: 1-10.

Ota T, Asahina H, Park SH, Huang Q, Minegishi T, Auersperg N, Leung PC. 2008. HOX cofactors expression and regulation in the human ovary. Reprod Biol Endocrinol 6: 49.

Paria BC, Reese J, Das SK, Dey SK. 2002. Deciphering the cross-talk of implantation: Advances and challenges. Science 296: 2185-2188.

Passner JM, Ryoo HD, Shen L, Mann RS, Aggarwal AK. 1999. Structure of a DNA-bound ultrabithorax-extradenticle homeodomain complex. Nature 397: 714-719.

Payson M, Leppert P, Segars J. 2006. Epidemiology of myomas. Obstet Gynecol Clin North Am 33: 1-11.

Pellegrini M, Pantano S, Lucchini F, Fumi M, Forabosco A. 1997. Emx2 developmental expression in the primordia of the reproductive and excretory systems. Anat Embryol (Berl) 196: 427-433.

Rackow BW, Taylor HS. 2010. Submucosal uterine leiomyomas have a global effect on molecular determinants of endometrial receptivity. Fertil Steril 93: 2027-2034.

Ramirez-Solis R, Zheng H, Whiting J, Krumlauf R, Bradley A. 1993. Hoxb-4 (Hox-2.6) mutant mice show homeotic transformation of a cervical vertebra and defects in the closure of the sternal rudiments. Cell 73: 279-294.

Revel A. 2012. Defective endometrial receptivity. Fertil Steril 97: $1028-1032$.

Satokata I, Benson G, Maas R. 1995. Sexually dimorphic sterility phenotypes in Hoxa10-deficient mice. Nature 374: $460-463$.

Scott MP. 1997. Hox genes, arms and the man. Nat Genet 15: $117-118$.

Scott MP, Weiner A. 1984. Structural relationships among genes that control development: Sequence homology between the Antennapedia, Ultrabithorax, and fushitarazu loci of Drosophila. Proc Natl Acad Sci 81: 4115-4119.

Senapati S, Barnhart K. 2011. Managing endometriosisassociated infertility. Clin Obstet Gynecol 54: 720-726.

Simeone A, Acampora D, Gulisano M, Stornaiuolo A, Boncinelli E. 1992a. Nested expression domains of four homeobox genes in developing rostral brain. Nature 358: 687-690.

Simeone A, Gulisano M, Acampora D, Stornaiuolo A, Rambaldi M, Boncinelli E. 1992b. Two vertebrate homeobox genes related to the Drosophila empty spiracles gene are expressed in the embryonic cerebral cortex. EMBO J 11: 2541-2550.

Sinclair DC, Mastroyannis A, Taylor HS. 2011. Leiomyoma simultaneously impair endometrial BMP-2-mediated decidualization and anticoagulant expression through secretion of TGF- $\beta 3$. J Clin Endocrinol Metab 96: 412421.

Smith C, Taylor HS. 2007. Xenoestrogen exposure imprints expression of genes (Hoxa10) required for normal uterine development. FASEB J 21: 239-246.

Strandell A, Sjögren A, Bentin-Ley U, Thorburn J, Hamberger L, Brännström M. 1998. Hydrosalpinx fluid does 
H. Du and H.S. Taylor

not adversely affect the normal development of human embryos and implantation in vitro. Hum Reprod 13: 2921-2925.

Studer M, Lumsden A, Ariza-McNaughton L, Bradley A, Krumlauf R. 1996. Altered segmental identity and abnormal migration of motor neurons in mice lacking Hoxb-1. Nature 384: 630-634.

Sugiura-Ogasawara M, Ozaki Y, Sonta S, Makino T, Suzumori K. 2005. Exposure to bisphenol A is associated with recurrent miscarriage. Hum Reprod 20: 2325-2329.

Surrey ES, Lietz AK, Schoolcraft WB. 2001. Impact of intramural leiomyomata in patients with a normal endometrial cavity on in vitro fertilization-embryo transfer cycle outcome. Fertil Steril 75: 405-410.

Suzuki M, Lee HC, Chiba S, Yonezawa T, Nishihara M. 2004 Effects of methoxychlor exposure during perinatal period on reproductive function after maturation in rats. $J R e-$ prod Dev 50: 455-461.

Svingen T, Koopman P. 2007. Involvement of homeobox genes in mammalian sexual development. Sex Dev 1: $12-23$.

Taylor HS. 2000. The role of HOX genes in the development and function of the female reproductive tract. Semin Reprod Med 18: 81-89.

Taylor HS. 2008. Endocrine disruptors affect developmental programming of HOX gene expression. Fertil Steril $\mathbf{8 9}$ e57-e58.

Taylor HS, Fei X. 2005. Emx2 regulates mammalian reproduction by altering endometrial cell proliferation. $\mathrm{Mol}$ Endocrinol 19: 2839-2846.

Taylor HS, Van den Heuvel GB, Igarashi P. 1997. A conserved Hox axis in the mouse and human female reproductive system: Late establishment and persistent adult expression of the Hoxa cluster genes. Biol Reprod 57: 1338 1345.

Taylor HS, Arici A, Olive D, Igarashi P. 1998. HOXA10 is expressed in response to sex steroids at the time of implantation in the human endometrium. J Clin Invest 101: 1379-1384.

Taylor HS, Bagot C, Kardana A, Olive D, Arici A. 1999a. HOX gene expression is altered in the endometrium of women with endometriosis. Hum Reprod 14: 1328-1331.
Taylor HS, Igarashi P, Olive D, Arici A. 1999b. Sex steroids mediate HOXA11 expression in the human peri-implantation endometrium. J Clin Endocrinol Metab 84: 11291135.

Troy PJ, Daftary GS, Bagot CN, Taylor HS. 2003. Transcriptional repression of peri-implantation EMX2 expression in mammalian reproduction by HOXA10. Mol Cell Biol 23: $1-13$.

Verkauf BS. 1987. Incidence, symptoms, and signs of endometriosis in fertile and infertile women. J Fla Med Assoc 74: 671-675.

Verlinsky Y, Morozov G, Gindilis V, Strom CM, Freidin M, Rechitsky S, Verlinsky O, Ivakhnenko V, Zdanovsky V, Kuliev A. 1995. Homeobox gene expression in human oocytes and preembryos. Mol Reprod Dev 41: 127-132.

Warot X, Fromental-Ramain C, Fraulob V, Chambon P, Dolle P. 1997. Gene dosage-dependent effects of the Hoxa-13 and Hoxd-13 mutations on morphogenesis of the terminal parts of the digestive and urogenital tracts. Development 124: 4781-4791.

Wu Y, Halverson G, Basir Z, Strawn E, Yan P, Guo SW. 2005. Aberrant methylation at HOXA10 may be responsible for its aberrant expression in the endometrium of patients with endometriosis. Am J Obstet Gynecol 193: 371-380.

Wu Y, Strawn E, Basir Z, Halverson G, Guo SW. 2007. Aberrant expression of deoxyribonucleic acid methyltransferases DNMT1, DNMT3A, and DNMT3B in women with endometriosis. Fertil Steril 87: 24-32.

Yau TO, Kwan CT, Jakt LM, Stallwood N, Cordes S, Sham MH. 2002. Auto/cross-regulation of Hoxb3 expression in posterior hindbrain and spinal cord. Dev Biol 252: 287300 .

Zeyneloglu HB, Arici A, Olive DL. 1998. Adverse effects of hydrosalpinxon pregnancy rates after in vitro fertilization-embryo transfer. Fertil Steril 70: 492-499.

Zhang Y, Huang Q, Cheng JC, Nishi Y, Yanase T, Huang HF, Leung PC. 2010. Homeobox A7 increases cell proliferation by up-regulation of epidermal growth factor receptor expression in human granulosa cells. Reprod Biol Endocrinol 8: 61. 


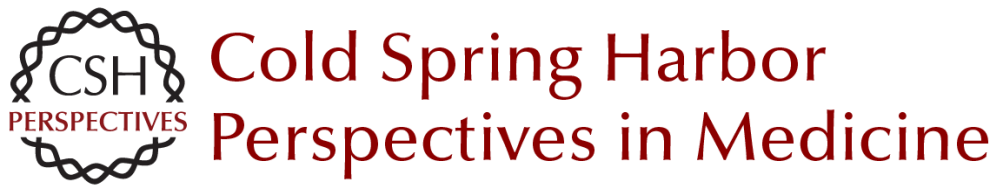

\section{The Role of Hox Genes in Female Reproductive Tract Development, Adult Function, and Fertility}

Hongling Du and Hugh S. Taylor

Cold Spring Harb Perspect Med 2016; doi: 10.1101/cshperspect.a023002 originally published online November 9, 2015

Subject Collection Molecular Approaches to Reproductive and Newborn Medicine

Intergenerational Transfer of Epigenetic

Information in Sperm

Oliver J. Rando

\section{Effects of Maternal Obesity on Fetal Programming: Molecular Approaches Caterina Neri and Andrea G. Edlow}

The Neonatal Salivary Transcriptome Jill L. Maron

The Role of Hox Genes in Female Reproductive Tract Development, Adult Function, and Fertility Hongling Du and Hugh S. Taylor

\section{Molecular Cross-Talk at the Feto-Maternal Interface}

Gendie E. Lash

\section{Molecular Regulation of Parturition: A Myometrial Perspective \\ Nora E. Renthal, Koriand'r C. Williams, Alina P. Montalbano, et al.}

Genome-Wide Sequencing for Prenatal Detection of Fetal Single-Gene Disorders Ignatia B. Van den Veyver and Christine M. Eng

MicroRNA in Ovarian Biology and Disease Lynda K. McGinnis, Lacey J. Luense and Lane K. Christenson
A Molecular Perspective on Procedures and Outcomes with Assisted Reproductive Technologies Monica A. Mainigi, Carmen Sapienza, Samantha Butts, et al.

Whole-Exome Sequencing and Whole-Genome Sequencing in Critically III Neonates Suspected to Have Single-Gene Disorders

Laurie D. Smith, Laurel K. Willig and Stephen F. Kingsmore

Noninvasive Antenatal Determination of Fetal

Blood Group Using Next-Generation Sequencing Klaus Rieneck, Frederik Banch Clausen and Morten Hanefeld Dziegiel

Potential Uses and Inherent Challenges of Using Genome-Scale Sequencing to Augment Current Newborn Screening Jonathan S. Berg and Cynthia M. Powell

Molecular Regulation of Parturition: The Role of the Decidual Clock Errol R. Norwitz, Elizabeth A. Bonney, Victoria V. Snegovskikh, et al.

Molecular Mechanisms of Preeclampsia Tammy Hod, Ana Sofia Cerdeira and S. Ananth Karumanchi

Noninvasive Prenatal Screening for Genetic Diseases Using Massively Parallel Sequencing of Maternal Plasma DNA Lyn S. Chitty and Y. M. Dennis Lo

Confrontation, Consolidation, and Recognition: The Oocyte's Perspective on the Incoming Sperm David Miller

For additional articles in this collection, see http://perspectivesinmedicine.cshlp.org/cgi/collection/ 